\title{
The Status of Outsourcing Services in a Specialized Tehran Hospital Using SWOT
}

\author{
Parisa Mehdizadeh $^{1}$, Nooredin Dopeykar ${ }^{2}$, Ezzatollah Gol-Alizadeh ${ }^{3}$, Maryam Yaghoubi ${ }^{4, *}$ \\ ${ }^{1}$ Health Economics Department, Health Management Research Center, Baqiyatallah University of Medical Sciences, Tehran, IR Iran \\ ${ }^{2}$ Research Center for Prevention of Oral and Dental Diseases, Baqiyatallah University of Medical Sciences, Tehran, IR Iran \\ ${ }^{3}$ Support Deputy of Islamic Republic of Iran's Medical Council, Tehran, IR Iran \\ ${ }^{4}$ Health Management Research Center, Baqiyatallah University of Medical Sciences, Tehran, IR Iran
}

*Corresponding Author: Maryam Yaghoubi, PhD, Assistant Professor, Health Management Research Center, Baqiyatallah University of Medical Sciences, Tehran, IR Iran. Tel: +98-2182482474, Email: yaghoobbi@yahoo.com

Received: 5 Apr. 2015; Accepted: 28 May. 2016; Online Published: 27 Aug. 2016

\begin{abstract}
Background: Outsourcing in healthcare is a cost-effective strategy that reduces costs and increases service quality. Managers must attempt to outsource healthcare services using scientific methods.

Objective: This study is a strategic analysis of the outsourcing of health services in one specialty and subspecialty hospital in Tehran.

Methods: This mixed method study (quantitative-qualitative) was performed in 2014 at one of the biggest specialty hospitals in Tehran. Data was collected through interviews, focus discussion groups (FDG), and the internal and external factors evaluation matrix. The study population comprised managers and directors of the hospital. Data was analyzed using Excel 2010 software and SWOT analysis.

Results: The final scores for internal and external factors were 2.16 and 2.68 , respectively, indicating the hospital had a conservative strategic position for choosing outsourcing strategies.

Conclusion: Since this hospital had a conservative strategic position in outsourcing, managers were able to change their outsourcing strategy while considering its advantages and disadvantages and determining the type of services to be outsourced.
\end{abstract}

Keywords: Outsourcing, Hospital Administration, SWOT

\section{Background}

Today, the health system is one of the largest sectors of the world's economy [1], and in the process of globalization, this sector has grown faster globally than any other [2]. One principal concern of health systems for poor and rich countries alike is financial security, as the health sector includes $9 \%$ of the world's production [3]. Everyday increases in healthcare costs have challenged economic specialists and managers to identify new methods for reducing costs and increasing income $[4,5]$.

Healthcare investments and economic development share a mutual relationship [6]. Therefore, the principles of economic science must be utilized to combine factors and production resources and to present services. One strategy effective in reducing costs and increasing efficiency is outsourcing [7, 8]. By outsourcing services, professional organizations can better focus on the added value of activities and, as a result, increase the effectiveness of their activities [8]. Outsourcing health system reforms is a strategy that promotes the effectiveness of the health system. Furthermore, it is a cost-effective solution that prepares health-provider organizations for competition and, as a result, allows them to provide optimal and high-quality health services for patients [9]. Currently, outsourcing health services is a very hot topic in most countries where many hospital services are outsourced [10, 11]. The implementation of outsourcing in health organizations has a relatively long history. One method of using the expertise and empowerment of the private sector is to implement part of an organization's activities to this sector - in other words, to outsource [12].
Fredland studied outsourcing in terms of transaction costs and noted a growing trend towards private provision of some services, even in developed countries [13]. Locke studied outsourcing in defensive sectors and found the use of private solutions for products of providing order and public security to be appropriate. He concluded that, in the case of protective and refining systems, the processes and the procedures of outsourcing will permit the armed forces of the United States to achieve their goals [14].

Bellenghi et al. pointed out in their study that, according to the Association of Health Information Outsourcing Services (AHIOS), most United States hospitals (nearly 80\%) have outsourced the provision of medical information to private services so as to reduce their executive burden. Also, using the power of the private sector to provide such services reduced costs by up to $\$ 2.6$ million [15].

Studies conducted in developing countries have identified barriers to outsourcing as being the small number of specific outsourcing cases, the lack of trust between operator and outsourcer, the lack of necessary laws, and the lack of resources in controlling information [16].

To date in Iran, little research has been done on outsourcing in specialized organizations; however, a few examples exist. The 2010 study by Isaie et al. considered outsourcing as an effective strategy for correcting and improving the consumption model in support of the armed forces (12).

SWOT is a common tool used in strategic management. One Netherlands hospital showed that $80 \%$ of health managers used this technique [17]. This tool can also be effective in facilitating the implementation of strategies in health organizations [18-20]. This tool helps make 
organizations in the market efficient by providing an awareness of the internal and external forces of success or failure [21].

\section{Objective}

The present study aimed to examine the strengths and weaknesses, opportunities and threats of outsourcing in one specialized hospital and analyze the strategic status using a SWOT model.

\section{Methods}

The present implicational study was conducted using the combination method in qualitative and quantitative phases. This study was conducted in 2014 at one specialized hospital in Tehran. The study population of this research included managers, professionals, and technical experts in the field of programming. For the qualitative phase, 5 members of the research community were selected for participation through purposive sampling in which the subjects are preferably selected based on the objectives of the research and not on random selection. The selection criteria of these people included management experience of more than 5 years of work in the studied hospital.

In this phase of the study, semi-structured interviews and focus discussion group (FDG) sessions were used to collect the overall views of the experts on the strengths, weaknesses, opportunities, and threats of outsourcing hospital services. In the second phase (quantitative), a checklist was developed for use in analyzing outsourcing strategic services in specialized hospitals. This questionnaire included 37 items regarding internal factors (22 items) and external factors (15 items). Internal factors included strengths (13 items) and weaknesses (improvable) (9 items), and external factors included opportunities (6 items) and threats (9 items). The questionnaire was given to 14 managers of various sections (hospital, nursery, and treatment sector managers) selected by the convenient sampling method. In completing the questionnaire, managers were first asked to assign the greatest coefficient to the factor that had the greatest impact on outsourcing hospital services, regardless of whether the item was considered a strength, weakness that could be improved, an opportunity, or a threat for the hospital. The total of the coefficients for each the segments of internal and external factors was 100 . Then, each of these components was scored from 1 (major weakness) to 4 (very high strength).

The final score of each item was obtained by multiplying the coefficient by the score. Analyses were performed using Excel software 2010 and SWOT analysis. To determine the strategic situation in this analysis, each item's coefficient was first multiplied by its score, and that resulted in the final score. Then, the final scores were added up, the mean was multiplied by the internal and external factors, and that number was divided by 100 . In this analysis, the final score for both internal and external factors was a number between 1 and 4 with a mean of 2.5. A final score less than 2.5 indicated that the organization was weak regarding the factors (internal or external), and a score greater than 2.5 indicated the organization's strength in the factors (internal or external). Finally, the strategic situation of the studied hospital was determined by the total of internal and external factors in the matrix of internal and external factors. This matrix included defensive, conservative, competitive, and invasive situations for which the organization determined each of their strategies accordingly [22].

\section{Results}

As Table 1 shows, the internal factors with the highest scores in strength were "respecting the principles of patients' rights" and "using modern diagnostic and treatment equipment"; those with the lowest scores were "access to various treatment options" and "skilled and experienced nursing staff".

Table 1. Assessment and analysis of internal and external factors in outsourcing hospital services

\begin{tabular}{|c|c|c|}
\hline No. & Items & $\begin{array}{l}\text { Final } \\
\text { Score }\end{array}$ \\
\hline \multicolumn{3}{|c|}{ IFE Internal Factor Evaluation, Strength } \\
\hline S1 & Efforts to improve the quality of services & 6.58 \\
\hline S2 & Creating competition between departments & 8.56 \\
\hline S3 & Motivating hospital personnel to outsource & 7.51 \\
\hline S4 & Using modern medical and diagnostic equipment & 12.68 \\
\hline S5 & Using expert and experienced doctors & 7.10 \\
\hline S6 & Skilled nursing staff & 4.92 \\
\hline S7 & Having proper hospital wards & 5.27 \\
\hline S8 & Access to different medical services & 3.97 \\
\hline S9 & $\begin{array}{c}\text { Appropriate duration of hospital stay of patients in } \\
\text { wards }\end{array}$ & 5.69 \\
\hline S10 & Optimal bed turnover & 5.48 \\
\hline S11 & $\begin{array}{l}\text { Efforts to protect and promote the satisfaction of } \\
\text { physicians, staff and patients }\end{array}$ & 7.19 \\
\hline S12 & High speed in service delivery & 12.40 \\
\hline S13 & Respecting the patients' rights & 14.18 \\
\hline \multicolumn{3}{|c|}{ IFE Internal Factor Evaluation, Improvable } \\
\hline W1 & $\begin{array}{l}\text { Lack of expert human resources in some medical } \\
\text { fields }\end{array}$ & 12.66 \\
\hline W2 & $\begin{array}{l}\text { Lack of international credibility to attract foreign } \\
\text { patients }\end{array}$ & 12.10 \\
\hline W3 & $\begin{array}{c}\text { Managers' views towards inefficiency of } \\
\text { outsourcing services }\end{array}$ & 10.08 \\
\hline W4 & $\begin{array}{c}\text { Inability of managers to outsource due to legal } \\
\text { restrictions }\end{array}$ & 15.02 \\
\hline W5 & Privatization as a threat to managers & 9.70 \\
\hline W6 & Lack of contracts with different insurers & 15.04 \\
\hline W7 & High risk for health & 9.58 \\
\hline W8 & $\begin{array}{l}\text { Reducing autonomy and decision-making in } \\
\text { hospitals }\end{array}$ & 10.40 \\
\hline W9 & $\begin{array}{l}\text { Imposing higher costs on patients and an overall } \\
\text { increase in costs }\end{array}$ & 19.53 \\
\hline & Final score of internal factors & 215.63 \\
\hline \multicolumn{3}{|c|}{ EFE External Factor Evaluation, Opportunity } \\
\hline 01 & $\begin{array}{c}\text { Tendency of patients to use modern equipment for } \\
\text { diagnosis and treatment }\end{array}$ & 24.44 \\
\hline $\mathbf{O 2}$ & Reducing government costs & 24.89 \\
\hline $\mathbf{O 3}$ & $\begin{array}{l}\text { Having a positive opinion of the hospital and its } \\
\text { aims in the private sector }\end{array}$ & 25.55 \\
\hline O4 & $\begin{array}{l}\text { Hospital dynamism in achieving international } \\
\text { standards }\end{array}$ & 28.51 \\
\hline 05 & $\begin{array}{l}\text { Increased interest and need to outsource services } \\
\text { and its application in different therapeutic areas }\end{array}$ & 19.18 \\
\hline O6 & Increasing the quality of services & 25.28 \\
\hline \multicolumn{3}{|c|}{ EFE External Factor Evaluation, Threat } \\
\hline T1 & $\begin{array}{l}\text { New, well-equipped, specialized treatment centers } \\
\text { in the city induces competition and risk of reduced } \\
\text { income }\end{array}$ & 11.24 \\
\hline $\mathbf{T 2}$ & Legal limits on outsourcing some services & 13.26 \\
\hline $\mathbf{T 3}$ & $\begin{array}{c}\text { Lack of access to expert and trained individuals to } \\
\text { assist managers in decision-making }\end{array}$ & 17.21 \\
\hline T4 & Lack of knowledge about outsourcing services & 10.40 \\
\hline T5 & $\begin{array}{l}\text { Profit-oriented attitude of the private sector in the } \\
\text { community }\end{array}$ & 14.72 \\
\hline T6 & $\begin{array}{c}\text { Weak support from human resources regarding } \\
\text { privatization }\end{array}$ & 12.80 \\
\hline T7 & Uncertainty in the economy of the country & 15.24 \\
\hline T8 & $\begin{array}{l}\text { Improper structure of rules and regulations in the } \\
\text { field of privatization }\end{array}$ & 16.25 \\
\hline \multirow[t]{2}{*}{ T9 } & Uncertainty about the ability of the private sector & 8.27 \\
\hline & Final score of external factors & 267.5 \\
\hline
\end{tabular}


Among the improvable points, "the cost imposed on patients and increased overall hospital costs" and "no contract with various insurance companies" had the highest final scores, and "high-risk for health" and "privatization as a treat for managers" had the lowest final scores.

According to Table 1, the evaluation of external factors showed that "the efficiency of the hospital to meet international standards" and "the positive opinion of people towards private hospitals" had the highest final scores as opportunities, and "increasing willingness and need for outsourcing services in the health sector" had the lowest final score.

"The lack of access to qualified and trained people to help managers in decision-making" and "improper structure of laws and regulations in privatization" had the highest final scores as threats, and "lack of confidence in the empowerment of the private sector" and "lack of awareness of outsourcing services" had the lowest final threat scores.

Next, the strategic situation of the organization was evaluated. As seen in Tables (1) and (2), the final score for internal factors was 2.16, which is lower than the mean (2.5). The final score of external factors was 2.68 , which is higher than the mean (2.5). However, after determining the final score of the internal and external factors of the hospital, the strategic status of the hospital in outsourcing services could be determined.

As Figure 1 shows, the studied organization had a conservative situation in the strategic choice of outsourcing services in specialized hospitals.

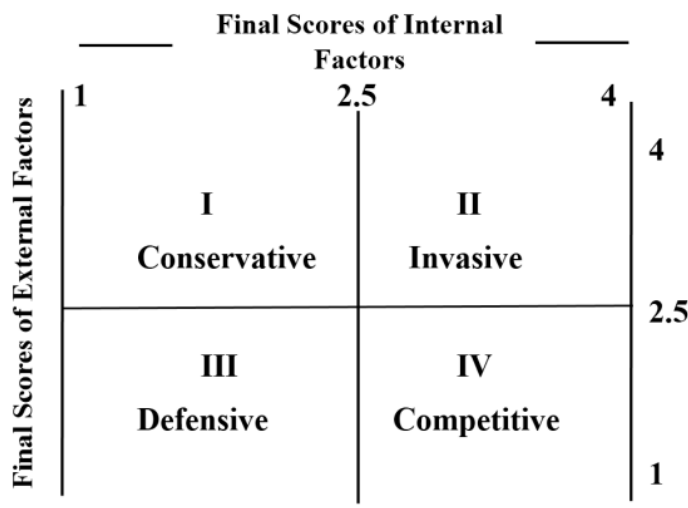

Figure 1. Strategic situation of the organization regarding the strategic choice of outsourcing services in specialized hospitals

\section{Discussion}

Outsourcing has advantages and disadvantages that each organization must consider and analyze. The process of outsourcing has its own characteristics in various organizations. Hence, in such a competitive area, having an advantage over other health organizations is necessary. Determining a hospital's strategic situation through strategic analysis is one tool that helps hospital managers increase their organization's competitive advantage [23].

According to the results of this research, respecting the principles of patients' rights had the highest strength in outsourcing services of a hospital. It should be noted that respecting the rights of patients is necessary for the execution of outsourcing services, and this factor is among the indexes that should be assessed when the success of incumbency reduction in outsourcing is being reviewed [24, 25]. Moreover, the human factor in an organization should be considered as an internal factor in the process of outsourcing [12]. Thus, attempts to protect and promote the satisfaction of patients, physicians, and personnel and to consider their rights are considered to be strengthen factors of outsourcing in the hospital in this study. Moschuris et al. stated that customer satisfaction and cost reduction are the most important factors affecting managers' decisions for the outsourcing of services. Moschuris et al. concluded that collaboration with the contract partner improves the quality of services, and most customers are satisfied with the performance of the organization [24].

The use of diagnostic and treatment equipment as one opportunity of the hospital has a high score. The emergence of health technologies in Iran's market and its role on attracting patients and improving health tourism has been mentioned in other studies [22, 26-28].

Today, assessing the precise strategic opportunities and threats of a hospital organization is very difficult; on the other hand, health care organizations should be able to identify and utilize large opportunities for survival in today's competitive market [29].

The results of the present study showed that the efficiency of a hospital in achieving international standards and attracting the positive opinion of people toward private hospitals are the most important opportunities in outsourcing hospital services. Other studies have shown the readiness of hospitals and the existence of an appropriate status in JCI standards for attracting medical tourists [30]. High-quality services would save costs and improve the opinion of employees, the satisfaction of patients, and the effectiveness of specialized service providers [31, 32]. Studies have pointed out that, in order to focus on the quality of services provided to hospital employees, which is a strength for increasing success in outsourcing services [22, 26], as it can be said regarding the impact of outsourcing on the increased quality of services, efficiency, and health improvement [22].

Health organizations extensively seek methods to increase their competitiveness and profits. Obtaining a competitive advantage by using new technologies and management skills is one of the biggest challenges for most organizations. With respect to these opportunities in hospitals and considering the fact that the benefits of successful outsourcing improve the quality of an organization's activities, such an organization can focus on the competitive advantage [32].

The most important factors considered as weaknesses in hospital outsourcing is the imposition of high costs upon patients and the lack of an insurance contract. In a study by Ansari et al., inappropriate insurance coverage and costs were two principal concerns for patients in choosing a hospital. If the hospital has inappropriate insurance contracts or treatment costs are too steep for patients, the outsourcer faces defeat [33].

The final score of internal factors was 2.16, which is lower than the mean value (2.5) and indicates that the organization is in an unfavorable condition and cannot use its strengths to overcome its weaknesses. The final score of external factors was 2.68 , which is higher than the mean value (2.5); this indicates that the external factors are in the proper condition and the impact of threats can be reduced using existing opportunities. However, after determining the final scores of the hospital's internal and external factors, the strategic situation of the organization regarding outsourcing services can be determined so that afterwards an appropriate and efficient strategy for maximizing strengths and opportunities and minimizing weaknesses and threats could be developed [34]. 
The present results showed that the strategic situation of the studied hospital in outsourcing services was conservative. Many studies show the conservativeness of organizations in outsourcing some services $[22,35]$.

A study by Hsiao et al. indicated that in the hospitals of Taiwan, there is still a conservative willingness to outsource clinical units [36]. Young's study showed that other than radiology and pharmacy, no other service had been outsourced; hospital managers believed that the outsourcing of these services would not save money and would create some risks to patient care [35]. Where outsourcing nonclinical services has been widely successful in hospitals, the implementation of such a strategy in clinical services is associated with high risks. Even so, some studies such as one by Vining and Globerman in the US indicated that the outsourcing of nursery services to the private sector has doubled between 1994 and 1995 [37]. Most studies in other countries, however, showed a lack of willingness to outsource services [35-37].

\section{Conclusion}

Outsourcing has some advantages and disadvantages, and any organization can implement outsourcing by considering and analyzing them. Experience has shown that health organizations are advanced in different fields of science, technology, and equipment, as they have certain responsiblities for keeping information up-to-date in their mission areas. Such organizations use many management sciences, advanced technologies, and new strategies as a competitive advantage in keeping information on the range of their activities. Therefore, hospitals consider the advantages and disadvantages of outsourcing services and determine the type of services that can be outsourced to change their strategy. Given that outsourcing health services is a cost-effective solution that prepares health-provider organizations for competition and consequently providing optimal and high-quality health services, these organizations choose to implement outsourcing.

\section{Acknowledgements}

The authors express their appreciation for the assistance of their colleagues in this research, especially the collaboration of Dr. Mehrabi-Tavana who provided valuable views and suggestions. Also the authors would like to thank the "Clinical Research Development Unit" of Baqiyatallah Hospital for their kind cooperation.

\section{Authors' Contributions}

All authors contributed equally in the preparation of this paper.

\section{Conflict of Interest}

None.

\section{References}

1. Organization WH. The world health report 2000: health systems: improving performance: World Health Organization; 2000.

2. Thomas R. Health Services Marketing .Springer sciences. Tsuang Ming-Sion. A Marketing process-planning model for sinlau Christian hospital, Tainan, Taiwan. South Carolina: Univercity of South Carolina; 2008

3. Purreza A. The role of contractual arrangements in improving health sector performance; experience from countries of the Eastern Mediterranean Region: 2010. Tehran: Ministry of Health and Medical Education; 2010. p. 89

4. Sakharkar B. Principles of hospital administration and planning:
Jaypee Brothers Medical Publishers; 2009 doi: $10.5005 / \mathrm{jp} / \mathrm{books} / 10677$

5. Rogowski J, Jain AK, Escarce JJ. Hospital competition, managed care, and mortality after hospitalization for medical conditions in California. Health Serv Res. 2007;42(2):682-705. doi: 10.1111/j.1475-6773.2006.00631.x

6. Kessler D, McClellan M. The effects of hospital ownership on medical productivity. Rand J Econ. 2002;33(3):488-506. doi: 10.2307/3087469

7. Garner R. SWOT tactics: basics for Strategic Planning FBI Law Enforcement Bulletin 2005 [19 November 2015]. Available from: Http://findarticles.com/p/articles/Mi

8. Li B, He M, Cao J. [The SWOT analysis and strategic considerations for the present medical devices' procurement]. Zhongguo Yi Liao Qi Xie Za Zhi. 2006;30(3):206-8.

9. Karimi S, Agharahimi Z, Yaghoubi M. Impacts of outsourcing in educational hospitals in Iran: A study on Isfahan University of Medical Sciences-2010. J Educ Health Promot. 2012;1:25. doi 10.4103/2277-9531.99959

10. Albreht T. Privatization processes in health care in Europe-a move in the right direction, a 'trendy'option, or a step back? Eur J Public Health. 2009;19(5):448-50. doi: 10.1093/eurpub/ckp146

11. Altman DJ, Gunderman RB. Outsourcing: a primer for radiologists. J Am Coll Radiol. 2008;5(8):893-9. doi: 10.1016/j.jacr.2008.03.005

12. Liu X, Hotchkiss DR, Bose S. The effectiveness of contracting-out primary health care services in developing countries: a review of the evidence. Health Policy Plan. 2008;23(1):1-13. doi: 10.1093/heapol/czm042

13. Fredland JE. Outsourcing military force: A transactions cost perspective on the role of military companies. Defence Peace Econ. 2004;15(3):205-19. doi: 10.1080/10242690310001623410

14. Lock L. Is Military Outsourcing Out of Control? DTIC Document, 2006.

15. Bellenghi GM, Coffey B, Fournier JE, McDavid JP. Release of information are hospitals taking a hit? Attempts by state legislatures to reduce fees for release-of-information requests could make it unprofitable for outsourcing companies to provide this service, potentially leaving hospitals to bear the expense. Healthc Financ Manage. 2008;62(11):118-22.

16. Siddiqi S, Masud TI, Sabri B. Contracting but not without caution: experience with outsourcing of health services in countries of the Eastern Mediterranean Region. Bull World Health Organ. 2006;84(11):867-75.

17. van Wijngaarden JD, Scholten GR, van Wijk KP. Strategic analysis for health care organizations: the suitability of the SWOT-analysis. Int J Health Plann Manage. 2012;27(1):34-49. doi: 10.1002/hpm. 1032

18. Yüksel İ, Dagdeviren M. Using the analytic network process (ANP) in a SWOT analysis-A case study for a textile firm. Inform Sci. 2007;177(16):3364-82. doi: 10.1016/j.ins.2007.01.001

19. Adams J. Successful strategic planning: creating clarity. J Healthc Inf Manag. 2005;19(3):25.

20. Bart CK, Hupfer M. Mission statements in Canadian hospitals. J Health Organ Manag. 2004;18(2):92-110. doi: 10.1108/14777260410538889

21. Singh SP, Chauhan MK, Singh P. Using multicriteria futuristic fuzzy decision hierarchy in SWOT analysis: an application in tourism industry. Int J Operat Res Inf Sys. 2015;6(4):38-56. doi: 10.4018/IJORIS.2015100103

22. Yaghoubi M, Agha Rahimi Z, Javadi M. Strategic analysis and hospital's strategic position in marketing planning: a case study of a private hospital in the Isfahan. Health Inf Manage 2014;10(7):996.

23. Ferdosi M, Farahabadi M, Rejalian F, Haghighat P. Outsourcing of medical record unit services: case assessment Isfahans kashani hospital. Health Inform Manag. 2010;7:658-68.

24. Moschuris SJ, Kondylis MN. Outsourcing in public hospitals: a Greek perspective. J Health Organ Manag. 2006;20(1):4-14. doi: 10.1108/14777260610656534

25. Wiley A, Coe C. ASHP guidelines on outsourcing pharmaceutical services. Am J Health Syst Pharm. 1998;55(15):1611-7.

26. Ayoubian A, Tourani S, Dehaghi ZH. Medical tourism attraction of Tehran hospitals. Int J Travel Med Glob Health. 2014;1(2):95-8.

27. Tabibi SJ, Nasiripour AA, Ayubian A, Mahmoodabadi HB. The relation between information mechanisms and medical tourist attraction in Hospitals of Tehran, Iran. Director General. 2012;9(3).

28. Izadi M, Ayoobian A, Nasiri T, Joneidi N, Fazel M, Hosseinpourfard M. Situation of health tourism in Iran opportunity or threat. J Mil Med. 2012;14(2):69-75.

29. Sahney S, Banwet D, Karunes S. An integrated framework for quality in education: Application of quality function deployment, interpretive structural modelling and path analysis. Total Qual Manag 
Bus Excel. 2006;17(2):265-85 doi: 10.1080/14783360500450376

30. Zaboli R, Zarandi MRS, Ayoubian A. A comparison of service quality in teaching and non-teaching hospitals: the gap analysis. Int $\mathbf{J}$ Travel Med Glob Health. 2015;3(1):37-41. doi: 10.20286/ijtmgh030137

31. Ayoubian A, Dopeykar N, Mehdizadeh P, Hoseinpourfard M, Izadi M. Surveying the Quality of care services in a military health center according to the SERVQUAL model. J Mil Med. 2015;16(4):225-9.

32. Mayson B, Fleshner N, So A. Physician opinion of the privatization of health care services in Canada: a survey of Canadian urologists by the Canadian Urological Association Socioeconomic Committee. Can Urol Assoc J. 2009;3(3):193-7.

33. Ansary M, Rahimi A, Yarmohamadian M, Yaghobbi M. SWOT analysis in school of management and medical information science,
Isfahan University of Medical Sciences. J Health Admin 2009;12(36):33-8.

34. Khodaverdi R ZB, E. The advantages, risks and challenges of outsourcing strategy. Roshd-e-Fanavari J. 2011(25):65-71.

35. Young S. Outsourcing in the Australian health sector: the interplay of economics and politics. Int J Public Sect Manag. 2005;18(1):2536. doi: $10.1108 / 09513550510576134$

36. Hsiao C-T, Pai J-Y, Chiu H. The study on the outsourcing of Taiwan's hospitals: a questionnaire survey research. BMC Health Serv Res. 2009;9(1):1. doi: 10.1186/1472-6963-9-78

37. Vining AR, Globerman S. Contracting-out health care services: a conceptual framework. Health Policy. 1999;46(2):77-96. doi: 10.1016/S0168-8510(98)00056-6 